\title{
Reasons for and Scenarios Associated With Failure to Cease Smoking: Results From a Qualitative Study Among Smokers Who Had Unsuccessfully Attempted to Quit
}

\section{Krzysztof Buczkowski ( $\sim$ buczkowskik@cm.umk.pl)}

Department of Family Medicine, Nicolaus Copernicus University, Torun, Poland; https://orcid.org/00000002-7700-0952

\section{Magdalena Dachtera-Frackiewicz}

Uniwersytet Mikolaja Kopernika w Toruniu

\section{Dorota Luszkiewicz}

Uniwersytet Mikolaja Kopernika w Toruniu

Katarzyna Klucz

Uniwersytet Mikolaja Kopernika w Toruniu

\section{Jolanta Sawicka-Powierza}

Uniwersytet Medyczny w Bialymstoku

\section{Ludmila Marcinowicz}

Uniwersytet Medyczny w Bialymstoku

Research article

Keywords: smoking cessation, relapse, primary care, qualitative research

Posted Date: August 12th, 2020

DOI: https://doi.org/10.21203/rs.3.rs-42358/v1

License: (c) (i) This work is licensed under a Creative Commons Attribution 4.0 International License. Read Full License

Version of Record: A version of this preprint was published at Patient Preference and Adherence on September 1st, 2021. See the published version at https://doi.org/10.2147/PPA.S320798. 


\section{Abstract}

Background: Most smokers attempt to quit smoking, but few are successful. Data regarding the reasons for this relapse and the course of the relapse process may be helpful for determining efficient methods of smoking cessation. This study aimed to identify the causes of and scenarios associated with smoking relapse after effective smoking cessation.

Methods: We conducted 20 semi-structured interviews with smokers who had previously unsuccessfully attempted to quit. The data underwent qualitative content analysis.

Results: Three major themes were identified: Reasons for smoking relapse; Smoking relapse scenarios; and Perception of the influence of personal environments, including family and physicians, on refraining from smoking after cessation. The first theme comprised the following subthemes: insufficient willpower and self-discipline, contact with smokers, exposure to stressful situations, lack of family support, weight gain, and insufficient improvement in one's mental and physical well-being. The second theme contained enjoyable social events, professional life, critical events, and encouragement to smoke from family members. The respondents frequently emphasized the large role of interaction with other smokers.

Conclusions: The predominant factors underlying smoking relapse include insufficient willpower and selfdiscipline and exposure to stress. The most frequent relapse scenario concerned experiencing negative or positive emotions when interacting with other smokers.

\section{Background}

Currently, almost 1.1 billion people worldwide smoke cigarettes, and almost half will die as a result of smoking-related diseases $[1,2]$. The annual number of deaths related to the global tobacco epidemic is continually rising, and currently exceeds seven million $[3,4]$.

The only methods of improving this situation are by preventing people from commencing smoking, which will bring results in the long term, and by increasing the number of people who are quitting smoking, which would be the fastest way of lowering tobacco-related mortality [5,6]. To this end, many countries have introduced multi-level campaigns to discourage smoking, involving measures such as high taxation of cigarettes or bans on advertising and sponsorship, and several have also conducted information campaigns aimed at preventing non-smokers from beginning smoking and at encouraging active smokers to stop smoking $[7,8]$. Moreover, many behavioral interventions and pharmacological treatments have been offered to active smokers to help them quit smoking [9-11].

As a result, the majority of current smokers have considered smoking cessation, and many have made attempts to quit [12]. Studies have shown that over one-third of daily smokers have attempted to quit over the past year, and that almost three-quarters have made such an attempt at least once in their lifetimes [13]. Unfortunately, most smoking-cessation attempts end in failure [14,15], and the majority of smokers make several attempts before achieving long-term abstinence [12]. 
When considering issues associated with smoking cessation, it is important to remember that commencing smoking depends mainly on influences from one's environment, while continuing to smoke after a certain time is the result of nicotine addiction [16]. For individuals with nicotine addiction, regular cigarette smoking maintains adequate plasma nicotine levels to prevent withdrawal symptoms, and it allows them to experience the rewarding effects associated with smoking [17]. Conversely, for such people, when plasma nicotine levels become inadequate, unpleasant symptoms of anxiety and stress present, and this creates a strong stimulus to smoke a cigarette [18]. Thus, the nature of nicotine addiction concerns the achieving of positive reinforcements, such as a decrease in anxiety, mood modulation, and avoidance of withdrawal symptoms [19]. Former smokers who are addicted to nicotine can also experience non-biological urges to smoke, such as when exposed to various situations during which they would have previously smoked; these urges persist long after withdrawal symptoms have subsided [16]. Smokers use cigarettes during various events, and making connections between particular situations, moods, or places can create smoking-related cues concerning the rewarding effects of nicotine [20]. During smoking-cessation attempts, these cues can trigger the breaking of abstinence.

The aforementioned biological conditions can be influenced by psychological conditions, such as personality, resistance to stress, and the presence of anxiety and/or depression [21-23]. Additionally, a large role is played by the environments in which the smoker lives and works as, on one hand, these may create circumstances that discourage smoking commencement or encourage smoking cessation while, on the other hand, they may promote smoking. A particularly important role in this regard is played by the person's close social circle, particularly in relation to the atmosphere of trust and support the people in this circle may create, as well as whether they smoke and whether they will help the former smoker continue his/her abstinence [24-26].

Smoking is a complex behavior and, when analyzing the process of smoking cessation in its entirety, all dimensions of this behavior must be taken into consideration. The available literature confirms that changing smoking behavior is a long-term process that can include repeated episodes of relapses and renewed quitting attempts [12]. The process of relapse, has been the subject of research for many years, as better understanding thereof may result in the development of more effective programs for smoking cessation.

Such previous studies, conducted mainly using quantitative methods, have shown, for example, that sex, age, socioeconomic status, age when beginning treatment, and level of addiction are related to the efficiency of a smoking-cessation attempt [27-29]. The majority of these studies of unsuccessful quitting activity have been primarily conducted in developed Western and Asian countries, where measures to discourage smoking have been implemented for several decades [12,14,15]. In contrast, little research has been conducted in countries where the smoking-reduction process has begun more recently. Although the number of smokers has decreased in both the former and latter groups of countries, the attitudes and behaviors of the smokers in these countries may differ across the two groups. In developed countries, where the smoking-reduction process is stabilized and has been ongoing for several years, subsequent generations have been growing up in a climate of various anti-nicotine campaigns. In the countries where 
this process began later and had a more turbulent course, many smokers, even young ones, have lived without smoking-related barriers and prohibitions; in fact, they have frequently been exposed to actions and messages promoting cigarette smoking. Moreover, the availability of medical assistance, smokingcessation services, and pharmacological treatment is much lower in poorer countries than in developed countries [30]. Currently, almost $80 \%$ of the world's smokers live in low- and middle-income countries, and the experiences of smokers in such areas may differ from those living in developed countries [1].

Poland, which has recently joined the group of high-income countries, has shown many positive changes in public health, including a reduction in tobacco smoking, in the last $20+$ years [31,32]. It previously had one of the world's highest rates of smoking consumption, but over the past several years it has shown a consistent and ongoing decrease in tobacco consumption $[31,33]$. For this reason, studies in such a country may provide useful data for countries in which smoking-reduction efforts remain in their formative stages. The present study is a continuation of a project that aimed to identify the factors that influence complex smoking behaviors from the perspective of genetic, personality, and social conditions of cigarette smoking $[23,34,35]$.

The specific aim of this study, conducted in a primary care setting, is to determine the causes of and scenarios underlying smoking relapse after earlier effective smoking cessation.

\section{Methods \\ 2.1. Design}

Qualitative studies are the most suitable methods of obtaining an in-depth understanding of analyzed phenomena [36]. Given that the present study sought to examine the phenomenon of failure to abstain from smoking, the qualitative approach represented the best method of exploring this issue [37].

Moreover, this study pertains to sensitive issues, such as the course of the addiction, failure to overcome addiction, close relationships, and working environment; for this reason, among the various qualitative study methods, a semi-structured interview approach was chosen. The semi-structured interviews conducted in this research were narrative in form, making it possible to gain an in-depth understanding of the analyzed issue, while also allowing the informants to feel at ease during individual meetings, discuss their experiences, and express their opinions regarding the questions under discussion [38].

\subsection{Participants, setting, and data collection}

This study was conducted between October 2015 and March 2016 at which point data saturation was achieved. Purposive samples of interview participants were recruited from three general practices in Bydgoszcz, Poland, that had a cooperative relationship with the Family Medicine Department of Nicolaus Copernicus University and two general practices in Bialystok, Poland, that had a cooperative relationship with the Family Medicine Department of the Medical University in Bialystok. Patients making regular visits to the practices and who fulfilled the criteria presented below were invited by the GPs or nurses to participate in the project. 
For participation in this research, individuals who were at least 18 years of age, who had made at least one unsuccessful attempt to quit smoking, and who had smoked at least 100 cigarettes in his/her lifetime before the attempt were targeted; an attempt to quit was defined as at least 24 hours of continuous tobacco abstinence.

Interviews were conducted in the general practices in Bydgoszcz by MDF (MD) and KB (MD, PhD) and in Bialystok by LM (PhD), and, all of whom were experienced in qualitative research methods, and in accordance with a topic guide. All participants were not known to researchers before the study. Before interview researchers presented themselves and explained reasons for doing the research.

The topic guide was developed based on a literature review and was tested and refined through a pilot study involving three people meeting the same inclusion criteria as stated above. The interviews began with an opening question followed by prompts, as shown in Table 1. These interviews lasted from 25 to 40 minutes, were audio-recorded, transcribed verbatim, and then anonymized. The interviews were conducted in an independent room, with only the participant and the interviewer present. There were no repeated interviews and participants did not comment transcripts and results.

Table 1

Topic guide for interviews.

\begin{tabular}{|ll|}
\hline Opening question & Have you ever tried to stop smoking? \\
\hline Prompt 1 & How many years have you been smoking? \\
\hline Prompt 2 & How many times have you tried to quit smoking? \\
\hline Prompt 3 & Why did you want to quit smoking? \\
\hline Prompt 4 & How long did you cease smoking? \\
\hline Prompt 5 & Can you tell me how you relapsed to smoking? \\
\hline Prompt 6 & What or who do you think was the reason you relapsed? \\
\hline Prompt 7 & How do you think your doctor could help you to refrain from smoking? \\
\hline Prompt 8 & Would you like to add something else about your experience? \\
\hline
\end{tabular}

After the 15th interview, data saturation was achieved. However, because further interviews had already been arranged, the team decided to conduct them.

\subsection{Data analysis}

This study is based on qualitative content analysis, as demonstrated by Granheim and Lundman [39], Sandelowski [40], and Hsieh and Shannon [41]. In this context, content analysis represents a technique of ordering and describing data. The semi-structured interview data were analyzed with the aim of establishing a straightforward descriptive summary of the informational content of the data. The stages of analysis included identification of meaning units, creating condensed descriptions of these units, 
coding and, finally, identification of subthemes and themes. The interviews were analyzed by a team of three researchers.

Two authors (KB and LM; male and female) independently analyzed the transcripts and identified meaning units.

These were subsequently condensed and independently labeled with various codes that provided general descriptions thereof (Table 2). The codes were finally juxtaposed and formulated into subthemes and themes. Then, KB and LM, together with a third researcher (MDF; female), discussed the definitions of the subthemes and themes over two meetings until a consensus was reached. The analysis revealed three major themes, which are described in the following section.

Table 2

Example of the content analysis procedure of deriving a meaning unit, a condensed meaning unit, interpretation, a subtheme, and a theme.

\begin{tabular}{|c|c|c|c|c|}
\hline Meaning Unit & $\begin{array}{l}\text { Condensed } \\
\text { meaning unit; a } \\
\text { description that } \\
\text { closely resembles } \\
\text { the text }\end{array}$ & $\begin{array}{l}\text { Interpretation } \\
\text { (Code) }\end{array}$ & Subtheme & Theme \\
\hline $\begin{array}{l}\text { I hadn't smoked for } 56 \\
\text { days, and I decided that, } \\
\text { since I hadn't smoked for } \\
\text { such a long time, I could } \\
\text { allow myself to smoke one } \\
\text { cigarette. My strong } \\
\text { willpower was then } \\
\text { broken. }\end{array}$ & $\begin{array}{l}\text { I did not smoke } \\
\text { for many days, } \\
\text { and thought I } \\
\text { could afford to } \\
\text { have one } \\
\text { cigarette. My } \\
\text { strong willpower } \\
\text { was then broken. }\end{array}$ & $\begin{array}{l}\text { Lack of strong } \\
\text { willpower and self- } \\
\text { discipline and } \\
\text { allowing oneself to } \\
\text { have "only one } \\
\text { cigarette" was an } \\
\text { important cause of } \\
\text { smoking relapse. }\end{array}$ & $\begin{array}{l}\text { Lack of } \\
\text { strong } \\
\text { willpower } \\
\text { and self- } \\
\text { discipline } \\
\text { as a reason } \\
\text { for } \\
\text { smoking } \\
\text { relapse. }\end{array}$ & $\begin{array}{l}\text { Reasons } \\
\text { for } \\
\text { smoking } \\
\text { relapse. }\end{array}$ \\
\hline
\end{tabular}

\section{Results}

Twenty semi-structured interviews were conducted. During recruitment, six people refused to participate in the study. The participants comprised seven women and 13 men, with a mean age of 43 (2469 years). The women were older (mean age: 49 years) than the men (mean age: 39 years). The average smoking duration was approximately 21 years (ranging from six to 40 years), and was shorter in men (mean duration: 18 years) than in women (mean duration: almost 25 years). Four participants had made one ineffective attempt to quit smoking, one participant had made over a dozen, and the others $(n=15)$ had made between one and 10 such attempts. The participants' characteristics are shown in Table 3. None of the participants had attended any smoking-cessation clinics and none had received any psychological assistance. They sporadically utilized nicotine replacement therapy. The vast majority of smoking-cessation attempts were based on the "cold turkey" method (i.e., depending only on one's own willpower to resist smoking-related cravings and urges). Some of the participants reported informing physicians that they smoked. However, this did not constitute sourcing systematic help for a smoking- 
cessation attempt; instead, it was determined to represent sourcing of motivation from a physician to cease smoking.

Table 3

Participants' characteristics.

\begin{tabular}{|c|c|c|c|}
\hline $\begin{array}{l}\text { Participant } \\
\text { number }\end{array}$ & Gender & Smoking duration (years) & Number of attempts \\
\hline 1 & M & 12 & 2 \\
\hline 2 & M & 7 & 2 \\
\hline 3 & $\mathrm{~F}$ & 10 & 1 \\
\hline 4 & $\mathrm{~F}$ & 35 & 8 \\
\hline 5 & $M$ & 18 & 1 \\
\hline 6 & $M$ & 6 & Several \\
\hline 7 & $M$ & 12 & 3 \\
\hline 8 & $M$ & 9 & 4 \\
\hline 9 & $M$ & 22 & 1 \\
\hline 10 & M & 15 & 4 \\
\hline 11 & $\mathrm{~F}$ & 35 & 5 \\
\hline 12 & $M$ & 33 & Several \\
\hline 13 & $\mathrm{~F}$ & 30 & 4 \\
\hline 14 & M & 22 & $>12$ \\
\hline 15 & M & 20 & 5 \\
\hline 16 & M & 40 & 2 \\
\hline 17 & $\mathrm{~F}$ & 20 & Several \\
\hline 18 & $\mathrm{~F}$ & 22 & 3 \\
\hline 19 & $\mathrm{~F}$ & 20 & 1 \\
\hline 20 & $M$ & 40 & 2 \\
\hline
\end{tabular}

Detailed analysis of the transcripts of the in-depth interviews uncovered the following themes: (1) Reasons for smoking relapse; (2) Smoking relapse scenarios; (3) Perception of the influence of personal environments, including family members and physicians, on refraining from smoking after cessation. Themes and subthemes are described below, with associated quotations from the participants. 


\subsection{Theme 1. Reasons for smoking relapse}

The participants were eager to highlight possible reasons for their failure to cease smoking, and described the course of their failed attempts. The majority of the participants provided several reasons for their smoking relapse; meanwhile, some participants only gave a single reason for their failure, most likely its major cause (Table 4).

Table 4

Reasons for failure to cease smoking.

\begin{tabular}{|ll|}
\hline Reasons & Participant number \\
\hline Insufficient willpower and self-discipline & $1,2,3,4,6,7,9,10,12,14,17,19$ \\
\hline Contact with smokers & $3,6,8,9,16,17$ \\
\hline Exposure to stressful situations & $3,5,11,15$ \\
\hline Lack of family support & $8,13,18,20$ \\
\hline Weight gain & 18,19 \\
\hline Insufficient improvement in one's mental and physical well-being & 20 \\
\hline
\end{tabular}

The following reasons for failure to abstain from smoking were established: insufficient willpower and self-discipline $(n=12)$, contact with other smokers $(n=6)$, exposure to stressful situations (in professional and daily life; $n=4)$, lack of family support $(n=2)$, weight gain $(n=2)$, and insufficient improvement in one's mental and physical well-being $(n=1)$.

\subsubsection{Insufficient willpower and self-discipline}

Most participants $(n=12)$ mentioned insufficient willpower and self-discipline as the only or most important reason for their failure. This indicated that it was a personal quality, and not external circumstances, that the participants most frequently considered the reason for their failure. In their opinion, over time their initial strong willpower and self-discipline weakened, and the risk of smoking a cigarette increased. Smoking the first cigarette after the cessation attempt was considered an important moment that was a result of their weakened willpower and self-discipline. Most frequently, smoking this one cigarette led to a complete failure in the cessation attempt; that is, a relapse to smoking. This is exemplified by the following statement:

I think this relates to a lack of self-discipline. Eventually, after some time, not too long, a person just lets themselves go. If they smoke one cigarette, nothing will happen, but then they have another one, a third one, a fourth one (Participant 2).

Some participants were unaware that smoking one cigarette could mean a relapse to addiction. They believed that their strong willpower would make it possible to maintain abstinence after such an incident, 
but this assumption was usually incorrect. As shown in the example below, after smoking the first cigarette they lacked the willpower to avoid relapsing to smoking.

I hadn't smoked for 56 days, and I decided that, since I hadn't smoked for such a long time, I could allow myself to smoke one cigarette. My strong willpower was then broken (Participant 9).

\subsubsection{Contact with smokers}

Another reason concerned contact with other tobacco smokers. According to the participants, the presence in their close environments of smokers who were not trying to quit made it difficult to refrain from smoking. The example below illustrates how spending time among smokers weakens one's will to remain abstinent:

As you have noted, quite a lot of people smoke at our workplace. The daily contact with smokers definitely somehow broke my strong willpower (Participant 3).

Another participant admitted that, for him/her, spending time among smokers caused the most difficulty regarding maintaining abstinence; concurrently, he/she emphasized that when he/she was among nonsmokers, he/she did not feel the temptation to smoke. Unfortunately, spending time among smokers resulted in failure for him/her.

Spending time with tobacco smokers or in rooms where someone was smoking. It was most difficult when I could smell the smoke; the smell. When I was in a room with non-smokers, there was no such temptation (Participant 9).

Some participants emphasized that their attempts to refrain from smoking were aided by a lack of cigarettes and smokers in their close environments.

In my case, it was much more helpful if I didn't see cigarettes, if they weren't around, and if someone didn't leave to smoke. For people with an addiction, like smokers, it is helpful not to be exposed to it so much; rather, they should isolate themselves (Participant 6).

\subsubsection{Exposure to stressful situations}

The participants frequently mentioned stress; they often experienced it in their professional lives for example emergency services. Smoking at work made it easier to perform tasks, as it decreased stress and improved focus, but it also led to a relapse to smoking. This is illustrated by the following quote, in which the participant explains what he/she primarily blames for his/her relapse to smoking.

Professional life. Above all. The other factors have less influence. It's a fact, as they say, we go around at night, we need some kind of a kicker in these stressful situations, some kind of a booster. The effect of nicotine can get us going at three a.m. when we get a call (Participant 5).

Similarly, another participant stated that, on one hand, work-related activities distracted him/her from the temptation to smoke but, on the other hand, work-related stress was the reason for his/her relapse to 
smoking.

Work makes it possible to stop yourself from smoking; it's better when you are thinking about something else [...], the reason for the relapse was also work, the accompanying stress (Participant 15).

\subsubsection{Lack of family support}

For people who are quitting smoking, their personal environment has a large influence on whether they persevere. This pertains not only to the aforementioned professional environment, but also to relationships with close relatives and friends. For the participants, a particularly significant role was played by close acquaintances who were current smokers and who did not support the participants during their period of abstinence. Some participants specifically mentioned that their partner (husband or wife) was the person who had the biggest influence on their relapse to tobacco smoking. This is illustrated in the two examples below. First, a woman who was not supported by her smoking husband:

A smoking husband. He was a big obstacle, because after I talked to my female friends, they stopped offering me cigarettes. However, I didn't want to push my husband away, but he didn't support me. I felt such a grievance towards him because he didn't support me. [...] I somehow held out through parties, although I stood next to smokers. I was a little afraid of parties, but I made it through New Year's Eve (Participant 18).

Second, a man whose entire household were smokers, which meant that he could not rely on support from his close family members, and that he had easy access to cigarettes at home:

Everyone at home is a smoker. I knew there were cigarettes at home; I had access to them. Maybe if I'd been the only smoker, if nobody else at home smoked, I wouldn't have been able to get [cigarettes] from them (Participant 8).

\subsubsection{Weight gain}

A reason for failure that particularly pertained to women was weight gain. Observations confirm that smoking cessation is sometimes associated with weight gain. The participants explained that the fear of gaining weight caused them to relapse, or stated that they were discouraged from abstinence as a result of their consequent weight gain.

For me, and I think also for many women, the issue of gaining weight is a problem. I am afraid of this. I gained $10 \mathrm{~kg}$ in three months. This is a problem for every woman (Participant 18).

Another respondent made similar statements. She also referred to her family's tendency to become overweight or obese as an additional reason for her fear of experiencing further weight gain during her abstinence.

It may seem ridiculous, but it was because I started gaining weight. It disturbed me a lot; that I was putting on those kilos. In my family, there is a tendency to gain weight. I was afraid I would put on even 
more weight (Participant 19).

\subsubsection{Insufficient improvement in one's mental and physical well-being}

Some participants relapsed into addiction as a result of a lack of improvement in their mental and physical well-being. This was the case for a long-term smoker who had been diagnosed with chronic obstructive pulmonary disease (COPD). This person expected smoking cessation to result in a swift improvement in his/her mental and physical well-being and a decrease in his/her COPD symptoms. When that did not happen, his/her motivation to abstain from smoking decreased. This, in conjunction with a lack of support from his/her close family and friends caused the participant to relapse.

After a month of not smoking, I didn't notice any improvement in my well-being [...]. [My wife] encouraged me to smoke. The neighbor would come in the morning [...] and would sit with my wife, where they would smoke cigarettes together. She would smoke, my wife would smoke, what was I to do? (Participant 20).

\subsection{Smoking relapse scenarios}

Various situations contributed to the participants' relapses to smoking tobacco. These included social events, returning to work after a break, and critical events (e.g., an argument, an exam) that were accompanied by either positive or negative stress. These scenarios featured similar characteristics: the former smoker would spend time among smoking acquaintances, he/she would experience positive or negative emotions, and cues would appear. Then, insufficient willpower to avoid succumbing to these indirect or direct incentives, sometimes additionally weakened by alcohol consumption, led to a relapse (Fig. 1).

\subsubsection{Enjoyable social events}

The participants relapsed to smoking during family meetings and social events. In these situations, the relapse was frequently connected with drinking alcohol; for example, at a party or a family member's wedding. Weakened self-control regarding abstinence and the influence of smoking companions were also likely to contribute to the relapse. This is presented in the following two examples:

I attended a party where I smoked with some people, and then I began smoking again (Participant 2).

For me, this [relapse to smoking] is associated only with my brother's wedding. During the wedding, you know, there was alcohol. The next day, I was sober, but I also had already bought another pack (Participant 1).

Social meetings where alcohol consumption was absent could also have an effect. During these, encouragement from others to smoke, and probably the wish to do something enjoyable, were decisive factors leading to a relapse to smoking. The example below describes a meeting involving a mother and a daughter: 
All those times when I went to see someone, it didn't matter to me that other people were smoking. Mostly, this was when I went to see my daughter, [who I visit] once a week. But, sometimes there was such a desire. I think that if I hadn't taken the cigarette then, [I would not have relapsed]. [...] But, I thought, "whatever, one will not harm me." (Participant 4)

\subsubsection{Professional life}

Relapsing to smoking frequently occurred at work. On one hand, this was a result of stress, tiredness, or anxiety and, on the other, of the presence of smokers in the social circle and of easy access to cigarettes. An example of this is one respondent who returned to work after maternity leave, where her relapse was facilitated by interaction with smoking co-workers and being offered cigarettes.

I hadn't smoked for two years, and then I stopped nursing my baby. I returned to work and somehow II relapsed]. A friend offered one cigarette, and then another, and then a third one. Then, I had to buy some, because I would not smoke someone else's, and so, unfortunately, I went back to this addiction. [...] As you have noted, quite a lot of people smoke at our workplace. The daily contact with smokers definitely somehow broke my strong willpower (Participant 3).

Another respondent also emphasized the influence of the presence of smokers at his/her workplace in regard to his/her relapse to smoking.

That was where I first smoked a cigarette after a period of abstinence. At work, everyone is smoking, and so it starts with one cigarette, two cigarettes, and continues from there. (Laughter). By that point, after having taken a break from smoking, I had already begun to like them a lot. Someone offers one here, someone offers one there. From two to three to more or less 10 a day. First just a little, and then more and more (Participant 7).

\subsubsection{Critical events}

Some participants' return to smoking was assisted by exposure to particular stress-related situations (events). These included personal problems; for example, an argument with a spouse.

Some small misunderstandings. It was during the holidays, I was alone with my husband. One argument made me take a cigarette from him and I started smoking again (Participant 18).

Another situation concerned preparing oneself for an exam and experiencing a urge to re-adopt habits from university years; that is, smoking cigarettes during the exam period. The participant who experienced this situation also mentioned the availability of cigarettes at this time.

Then, there was an exam, for which I was studying at night. A habit I had from the time of my university studies was to do something while taking a break. Since cigarettes were [available] at home, because my wife is a smoker - I had one; then, I had two, and then I began to smoke on occasion for a month, and then I bought a pack (Participant 5).

\subsubsection{Encouragement to smoke from family members}


When not smoking, the participants frequently experienced anxiety and irritation, which was noticed by those in their close environments. In such situations, family members gave them permission, or even encouragement, to smoke, which would result in a relapse to smoking.

I felt anxiety. My wife would say "have a smoke, you'll be less anxious, you're exhausting yourself." I would tell my wife to stop smoking, but she didn't want to. She annoyed me (Participant 20).

3.3. Perception of the influence of personal environments, including family members and physicians, on refraining from smoking after cessation

The influence of one's environment on smoking relapse was mentioned by many participants, although it was not always perceived as the main reason for the relapse. Many participants stated that of great significance was whether people in their environments were smokers and, if so, whether they unnecessarily encouraged the participants to smoke.

The example below shows the importance of non-smoking environments, which promote smoking abstinence.

In my case, it was much more helpful if I didn't see cigarettes, if they weren't around, and if someone didn't leave to smoke. For people with an addiction, like smokers, it is helpful not to be exposed to it so much; rather, they should isolate themselves (Participant 6).

One example of the impact of the close personal environment concerned the influence of one's family. Having close family members who were non-smokers and who provided support represented a major example of positive influence.

The family can help. When I'm spending time with my children and grandchildren, who do not smoke, I do not smoke either (Participant 13).

This positive example of the influence of non-smoking family members contrasts with the following one, which shows that a lack of support from close acquaintances (in this case, spouses) is a significant detriment in refraining from smoking.

A smoking husband. He was a big obstacle, because after I talked to my female friends, they stopped offering me cigarettes. However, I didn't want to push my husband away; he didn't support me. I felt such a grievance towards him because he didn't support me. [...] I somehow held out through parties, although I stood next to smokers. I was a little afraid of parties, but I made it through New Year's Eve (Participant 18)

Physicians may also play a certain role in the environmental impact on smokers. This study established that physicians may have both positive and negative influences on one's smoking status. The positive influence presented by physicians, and their ability to present the negative effects of smoking, was connected, along with other factors, with the possibility of motivating the smoker. 
A physician can help by discussing the harmful effects of smoking. One physician got to me. He really scared me (Participant 11).

On the other hand, physicians could also have a negative influence, especially when they did not adopt an individual approach to the smoker, instead treating all smokers the same way.

Obviously, the physician repeats the same thing during all visits. I realized that this was a rote-learned statement about healthy lifestyle, etc. [...] I knew this was not individual; that the message was the same for every person (Participant 1).

Some participants indicated that the decision to stop smoking is individual and mainly concerns the smoker. Other people in smokers' environments may try to influence their decisions, but they are ultimately accountable for their actions and make the final decisions.

To be honest, nobody can help besides myself. This may sound self-centered, but I know this is so. I was once in a relationship with a girl who tried to convince me that I should not smoke, and nothing happened, I am still addicted (Participant 1).

\section{Discussion}

This study reveals the causes, underlying scenarios, and the role of personal environments regarding failure to maintain abstinence after smoking cessation. The major finding of this study is that the most important causes of a relapse are insufficient willpower and self-discipline and exposure to stress. Moreover, one's smoking environment also plays a large role, as it is usually in the company of other smokers, while experiencing positive or negative emotions, that one relapses to smoking.

Insufficient willpower was the most commonly given reason for failure, although the participants also mentioned several other contributing factors. The former smokers needed strong willpower to overcome the initial withdrawal symptoms. After quitting smoking, former smokers experience anxiety, irritability, and a depressed mood at levels that are comparable to those experienced by psychiatric patients [42,43]. The former smokers realize that smoking a cigarette might relieve these unpleasant experiences; thus, some immediately succumb to this temptation and relapse to smoking. Of those who manage to overcome such unpleasant symptoms, some adopt an independent approach, using willpower (the socalled "cold turkey" method). Meanwhile, others use pharmacotherapy to reduce the severity of the symptoms; although such medications have various mechanisms of action, their end result comprises a reduction in physical withdrawal symptoms and a lack of reinforcing effects if one happens to smoke a cigarette during abstinence [11]. Thus, using medication increases the chances of maintaining abstinence by several times $[44,45]$. Through lessening withdrawal symptoms, pharmacotherapy makes it easier for former smokers to concentrate on making changes to their psychological and social behaviors. Unfortunately, however, pharmacotherapy is used too rarely in the process of smoking cessation $[30,46]$. Many smokers are not aware of or underestimate the efficiency of pharmacotherapy in relation to smoking cessation [47]. In general, the participants in the present study used only the cold turkey method 
and did not seek professional help; they also sporadically used nicotine replacement therapy; this approach has also been reported in earlier studies conducted in eight European countries [30]. Later, when the withdrawal symptoms abate, to combat cravings it remains necessary to exercise willpower in certain situations, mostly those in which the person would usually have smoked. Our results pertaining to the essential role of strong willpower in this regard are consistent with those of Shaheen et al., who examined young smokers in Pakistan, a low-income country [48].

Spending time in a smoking environment has a negative impact on former smokers as, in such environments, there is a lack of social support to abstain from smoking, high tolerance for smoking, and exposure to smoking cues [49-51]. The participants mentioned that they would not have recommenced smoking had they not spent time with smokers. Smoking cues that appear in situations in which former smokers would have previously smoked (which causes the cues to function as triggers) seem to have key meaning $[20,52]$. It is the response to these cues that ultimately causes one to smoke. Our respondents described experiencing such situations when they spent time among smokers. People with lower education levels and who have lower socio-economic status are more likely to smoke, meaning former smokers from these social groups are more frequently exposed to smoking cues. Previous studies have highlighted the significant influence of the smoking environment on the occurrence of relapses to smoking, particularly among former smokers with lower education levels and lower income $[27,29,53]$.

The participants frequently emphasized that the attitude of their close social circle to smoking abstinence was a significant factor. Unfortunately, they had negative experiences in this regard, as having a spouse who smoked had a similar influence as spending time with other smokers - they were a source of stimuli to smoke. Lack of support from close social circles was listed as a reason for relapse; it also played a large role in the scenarios underlying such relapses. Similarly, several previous studies have also found that the smoking status of a former smoker's cohabitants has a large influence on the success of the quitting attempt, as living with a smoker decreases the chance of successful smoking cessation $[25,26]$.

On the other hand, support from non-smoking life partners and family members has been found to play a large positive role in successfully quitting smoking [54-56]. Further, living with a non-smoker or someone who has quit smoking in the past has a particularly beneficial impact $[15,57]$.

Among our participants, a recurring problem mentioned in connection with relapsing to smoking was weight gain, which was perceived-especially by women-as a deterioration of their physical appearance. These observations are consistent with the results of studies by Memon et al., who showed that postcessation weight gain promotes relapse. Moreover, these researchers showed that fear of unavoidable weight gain is also a barrier to attempting to cease smoking [58]. Thus, this appears to be a subject worth mentioning when preparing a smoker for smoking cessation. When there is a risk of such weight gain, an appropriate intervention should be provided, as gaining weight after smoking cessation means not only a change in one's physical appearance, but also a higher risk of diabetes and hypertension [59].

In all interviews, the relapse scenarios mentioned involved contact with smoking environments. Social meetings were particularly frequently discussed. Prior to smoking cessation, the participants would 
frequently smoke during informal meetings; consequently, during the cessation attempt such meetings induced a sudden impulse to smoke. If the person did not have sufficiently strong willpower (which was occasionally weakened by alcohol consumption in such situations), relapse would occur. The connection between alcohol consumption and tobacco smoking has been known for a long time [60,61]. Specifically, drinking alcohol is connected with increased nicotine dependence, less frequent undertaking of smokingcessation attempts, and a larger probability of relapse during smoking-cessation attempts $[60,62,63]$. When seeking to help smokers quit, it is worth keeping in mind that, in order to decrease the risk of a relapse, they should be advised to limit their alcohol consumption or to become temporarily entirely abstinent. Unfortunately, even after many years of abstinence a social meeting connected with alcohol consumption can constitute a relapse scenario [60].

Another finding was that stress plays a large role in unsuccessful smoking-cessation attempts. In our study, the participants frequently cited work-related stress as a trigger, which is consistent with reports from other studies $[64,65]$ When stress is accompanied by a lowered mood, the risk of relapse increases $[21,66]$. For example, Cooper et al. demonstrated that the occurrence of depression in participants is connected with more frequent undertaking of smoking-cessation attempts; unfortunately, it is also a predictor of more frequent relapses [67]. Further, Zvolensky et al. also confirmed that affective factors play an important role in quitting attempts [22].

For former smokers, exposure to stress causes an urge to smoke in order to alleviate the associated unpleasant sensations, as this had been an effective strategy prior to smoking cessation. A frequent scenario underlying smoking relapse, contact with other smokers, is also associated with stress, as the urge to relapse was especially strong when the participants experienced stress while in the company of other smokers. Thus, stress at work and during critical situations can lead to a relapse, particularly when cigarettes are easily available. Interventions for improving one's mood, especially among people with lowered mood, could be useful for preventing such a scenario [68].

Although a substantial majority of the participants did not use regular medical assistance in their smoking-cessation attempts, some discussed the role of physicians in smoking cessation. According to our participants, a physician can play a positive role, especially when they present to the smoker the consequences of tobacco smoking. However, to maximize the helpfulness of this advice, they should do so in an engaging manner, adapted for the given smoker. Wang et al. made similar observations in their studies; the respondents reported that health-care professionals who demonstrate sensitivity and true interest in helping the smoker represent notable sources of support when one is attempting to quit smoking [69]. Other studies have also highlighted the roles physicians and nurses can play in helping patients quit smoking [70-72]. This indicates that health-care professionals should seek to engage themselves in helping smokers quit, and should do so in a non-judgmental fashion, instead offering advice and support. This is particularly important when considering the effectiveness of anti-nicotine interventions and pharmacotherapy, which significantly increase the chance of successful smoking cessation [73-75]. In Poland, smokers can obtain anti-nicotine advice from general practitioners, but they have no access to smoking-cessation clinics, as no such institutions exist in many parts of the country 
[35]. Unfortunately, among European countries, smokers in Poland are least likely to use health professionals' advice to quit; this especially contrasts with the situation in countries in which the smoking-reduction process began several decades ago [30]. Pharmacotherapy involving nicotine replacement therapy, bupropion, cytisine, and varenicline are available, but they are not covered by health insurance, unlike in some developed countries [30]. In practice, this means that the majority of smokers attempt unassisted cessation: the cold turkey method and reduction in cigarette use before quitting completely [76].

\section{Limitations}

Although our study provides a new perspective on the smoking-cessation process in a country undergoing social changes, it has certain limitations. First, the present study is qualitative and the obtained results cannot be generalized to the entire smoking population. Second, despite having conducted interviews until data saturation was achieved, it is still possible that we did not establish all of the reasons for smoking-cessation failure. However, taking into account that, despite interviewing a narrow group of smokers who had unsuccessfully attempted to quit smoking, saturation was achieved after three-quarters of all interviews were conducted, the influence of these limitations should be limited. As we recruited participants from primary care settings, there may be a risk of selection bias, with more people with symptoms of smoking-related diseases among our participants than there are among the general population. However, this limitation does not seem to be significant in terms of the goals of this study.

Moreover, recall bias, resulting from misremembering facts or varying level of memory detail, is possible. However, it would appear that information such as the reasons for failure to quit smoking and the course of this process are usually well remembered by the smokers. Nevertheless, it would be possible to decrease the risk of this bias by collecting the opinions of the life partners of our smoking participants, which would enrich the results obtained.

\section{Conclusions}

This study revealed reasons smokers fail to quit smoking and scenarios that lead to a relapse. The causes of smoking-cessation failure are complex. However, insufficient willpower and self-discipline and exposure to stress predominate. This indicates that it is necessary to continually work with individuals who have quit smoking, providing support and helping them maintain self-discipline and abstinence.

Our study showcased the large role played by the social environment of the person who quits smoking. This pertains to the family as well as the work environment, and both should support tobacco abstinence. For smokers who have made repeated unsuccessful attempts to quit smoking, it may be necessary to make positive changes to both the smokers and their environments. 
In the case of people who have repeatedly relapsed to smoking, it might be useful to identify the particular scenario(s) in which relapse continually occurs and to develop a plan to help them avoid such a course of events. Based on the results of our study, it can also be surmised that providing high levels of access to cessation services and performing analysis of earlier failures could help smokers.

\section{Abbreviations}

GP

General Practitioner

COPD

Chronic Obstructive Pulmonary Disease

\section{Declarations}

Ethics approval and consent to participate: Ethical approval for this research was granted by the Bioethical Committee of the Collegium Medicum at Nicolaus Copernicus University, Bydgoszcz, Poland (KB 609/2015). Potential participants were provided with information regarding the study, and those who decided to participate gave oral informed consent which was saved at the beginning of the interview recording. This form of consent was in line with the committee's recommendation. Confidentiality and anonymity were assured.

Consent to publish: Not applicable

Availability of data and materials: The datasets analysed during the current study available from the corresponding author on reasonable request.

Competing interests: The authors declare no conflict of interest.

Funding: No funding was received

Author's Contributions: KB, DL and LM are responsible for the design of the study, with comments from MDF, JSP and KK. KB and LM categorized the data and discussed it with MDF. KB, DL, and JSP wrote the first draft of the manuscript, and LM and KK commented on draft versions of the manuscript. All authors read and approved the final manuscript.

Acknowledgements: Not applicable

\section{References}

1. World Health Organization. Tobacco Free Initiative. 2019; pp https://www.who.int/news-room/factsheets/detail/tobacco.

2. Lam, T.H. Absolute Risk of Tobacco Deaths: One in Two Smokers Will Be Killed by Smoking: Comment on "Smoking and All-Cause Mortality in Older People". Archives of internal medicine 2012, 
172, 845-846, doi:10.1001/archinternmed.2012.1927.

3. Mathers, C.D.; Loncar, D. Projections of global mortality and burden of disease from 2002 to 2030. PLoS medicine 2006, 3, e442, doi:10.1371/journal.pmed.0030442.

4. World Health Organization. Global Report. Mortality attributable to tobacco. 2012; $p$ https://apps.who.int/iris/bitstream/handle/10665/44815/9789241564434_eng.pdf? sequence $=9789241564431$.

5. Peto, R.; Lopez, A.D.; Boreham, J.; Thun, M.; Heath, C., Jr. Mortality from tobacco in developed countries: indirect estimation from national vital statistics. Lancet 1992, 339, 1268-1278, doi:10.1016/0140-6736(92)91600-d.

6. Lee, Y.; Kwon, S.; Moon, J.J.; Han, K.; Paik, N.J.; Kim, W.S. The Effect of Health-Related Behaviors on Disease Progression and Mortality in Early Stages of Chronic Kidney Disease: A Korean Nationwide Population-Based Study. Journal of clinical medicine 2019, 8, doi:10.3390/jcm8081100.

7. Bertollini, R.; Ribeiro, S.; Mauer-Stender, K.; Galea, G. Tobacco control in Europe: a policy review. European respiratory review : an official journal of the European Respiratory Society 2016, 25, 151157, doi:10.1183/16000617.0021-2016.

8. Springvloet, L.; Willemsen, M.C.; Mons, U.; van den Putte, B.; Kunst, A.E.; Guignard, R.; Hummel, K.; Allwright, S.; Siahpush, M.; de Vries, H., et al. Educational differences in associations of noticing antitobacco information with smoking-related attitudes and quit intentions: findings from the International Tobacco Control Europe Surveys. Health education research 2015, 30, 719-730, doi:10.1093/her/cyv037.

9. Godfrey, C.; Parrott, S.; Coleman, T.; Pound, E. The cost-effectiveness of the English smoking treatment services: evidence from practice. Addiction (Abingdon, England) 2005, 100 Suppl 2, 70-83, doi:10.1111/j.1360-0443.2005.01071.x.

10. Hollands, G.J.; Naughton, F.; Farley, A.; Lindson, N.; Aveyard, P. Interventions to increase adherence to medications for tobacco dependence. Cochrane Database of Systematic Reviews 2019, 10.1002/14651858.CD009164.pub3, doi:10.1002/14651858.CD009164.pub3.

11. Prochaska, J.J.; Benowitz, N.L. The Past, Present, and Future of Nicotine Addiction Therapy. Annual review of medicine 2016, 67, 467-486, doi:10.1146/annurev-med-111314-033712.

12. Borland, R.; Partos, T.R.; Yong, H.H.; Cummings, K.M.; Hyland, A. How much unsuccessful quitting activity is going on among adult smokers? Data from the International Tobacco Control Four Country cohort survey. Addiction (Abingdon, England) 2012, 107, 673-682, doi:10.1111/j.13600443.2011.03685.x.

13. Hughes, J.R.; Callas, P.W. Definition of a quit attempt: a replication test. Nicotine \& tobacco research : official journal of the Society for Research on Nicotine and Tobacco 2010, 12, 1176-1179, doi:10.1093/ntr/ntq165.

14. Hagimoto, A.; Nakamura, M.; Morita, T.; Masui, S.; Oshima, A. Smoking cessation patterns and predictors of quitting smoking among the Japanese general population: a 1-year follow-up study. Addiction (Abingdon, England) 2010, 105, 164-173, doi:10.1111/j.1360-0443.2009.02735.x. 
15. West, R.; McEwen, A.; Bolling, K.; Owen, L. Smoking cessation and smoking patterns in the general population: a 1-year follow-up. Addiction (Abingdon, England) 2001, 96, 891-902, doi:10.1046/j.13600443.2001.96689110.x.

16. Benowitz, N.L. Nicotine addiction. The New England journal of medicine 2010, 362, 2295-2303, doi:10.1056/NEJMra0809890.

17. Balfour, D.J. The neurobiology of tobacco dependence: a preclinical perspective on the role of the dopamine projections to the nucleus accumbens [corrected]. Nicotine \& tobacco research : official journal of the Society for Research on Nicotine and Tobacco 2004, 6, 899-912, doi:10.1080/14622200412331324965.

18. Le Moal, M.; Koob, G.F. Drug addiction: pathways to the disease and pathophysiological perspectives. European neuropsychopharmacology : the journal of the European College of Neuropsychopharmacology 2007, 17,377-393, doi:10.1016/j.euroneuro.2006.10.006.

19. Dani, J.A.; Heinemann, S. Molecular and cellular aspects of nicotine abuse. Neuron 1996, 16, 905908, doi:10.1016/s0896-6273(00)80112-9.

20. Davis, J.A.; Gould, T.J. Associative learning, the hippocampus, and nicotine addiction. Current drug abuse reviews 2008, 1, 9-19, doi:10.2174/1874473710801010009.

21. Siegel, A.; Korbman, M.; Erblich, J. Direct and Indirect Effects of Psychological Distress on StressInduced Smoking. Journal of studies on alcohol and drugs 2017, 78, 930-937, doi:10.15288/jsad.2017.78.930.

22. Zvolensky, M.J.; Johnson, K.A.; Leyro, T.M.; Hogan, J.; Tursi, L. Quit-attempt history: relation to current levels of emotional vulnerability among adult cigarette users. Journal of studies on alcohol and drugs 2009, 70, 551-554, doi:10.15288/jsad.2009.70.551.

23. Buczkowski, K.; Basinska, M.A.; Ratajska, A.; Lewandowska, K.; Luszkiewicz, D.; Sieminska, A. Smoking Status and the Five-Factor Model of Personality: Results of a Cross-Sectional Study Conducted in Poland. Int J Environ Res Public Health 2017, 14, doi:10.3390/ijerph14020126.

24. Sajjadi, H.; Jorjoran Shushtari, Z.; Mahboubi, S.; Rafiey, H.; Salimi, Y. Effect of socio-economic status, family smoking and mental health through social network on the substance use potential in adolescents: a mediation analysis. Public health 2018, 157, 14-19, doi:10.1016/j.puhe.2018.01.004.

25. Lewis, M.A.; McBride, C.M.; Pollak, K.I.; Puleo, E.; Butterfield, R.M.; Emmons, K.M. Understanding health behavior change among couples: an interdependence and communal coping approach. Social science \& medicine (1982) 2006, 62, 1369-1380, doi:10.1016/j.socscimed.2005.08.006.

26. Shoham, V.; Butler, E.A.; Rohrbaugh, M.J.; Trost, S.E. Symptom-system fit in couples: emotion regulation when one or both partners smoke. Journal of abnormal psychology 2007, 116, 848-853, doi:10.1037/0021-843x.116.4.848.

27. Lee, C.W.; Kahende, J. Factors associated with successful smoking cessation in the United States, 2000. American journal of public health 2007, 97, 1503-1509, doi:10.2105/ajph.2005.083527.

28. Ward, K.D.; Klesges, R.C.; Zbikowski, S.M.; Bliss, R.E.; Garvey, A.J. Gender differences in the outcome of an unaided smoking cessation attempt. Addictive behaviors 1997, 22, 521-533, 
doi:10.1016/s0306-4603(96)00063-9.

29. Marti, J. Successful smoking cessation and duration of abstinence--an analysis of socioeconomic determinants. Int J Environ Res Public Health 2010, 7, 2789-2799, doi:10.3390/ijerph7072789.

30. Hummel, K.; Nagelhout, G.E.; Fong, G.T.; Vardavas, C.I.; Papadakis, S.; Herbeć, A.; Mons, U.; van den Putte, B.; Borland, R.; Fernández, E., et al. Quitting activity and use of cessation assistance reported by smokers in eight European countries: Findings from the EUREST-PLUS ITC Europe Surveys. Tobacco induced diseases 2018, 16, doi:10.18332/tid/98912.

31. Neroth, P. Stubbing out Communist habits. Lancet 2005, 366, 109-110, doi:10.1016/s01406736(05)66848-1.

32. Polakowska, M.; Kaleta, D.; Piotrowski, W.; Topór-Mądry, R.; Puch-Walczak, A.; Niklas, A.; Bielecki, W.; Kozakiewicz, K.; Pająk, A.; Tykarski, A., et al. Tobacco smoking in Poland in the years from 2003 to 2014. Multi-centre National Population Health Examination Survey (WOBASZ). Polish archives of internal medicine 2017, 127, 91-99, doi:10.20452/pamw.3896.

33. Fagerström, K.; Boyle, P.; Kunze, M.; Zatonski, W. The anti-smoking climate in EU countries and Poland. Lung cancer (Amsterdam, Netherlands) 2001, 32, 1-5, doi:10.1016/s0169-5002(00)00203-8.

34. Buczkowski, K.; Sieminska, A.; Linkowska, K.; Czachowski, S.; Przybylski, G.; Jassem, E.; Grzybowski, T. Association between Genetic Variants on Chromosome 15q25 Locus and Several Nicotine Dependence Traits in Polish Population: A Case-Control Study. BioMed research international 2015, 2015, 350348, doi:10.1155/2015/350348.

35. Buczkowski, K.; Marcinowicz, L.; Czachowski, S.; Piszczek, E.; Sowinska, A. "What kind of general practitioner do I need for smoking cessation?" Results from a qualitative study in Poland. BMC family practice $\mathbf{2 0 1 3}$, 14, doi:10.1186/1471-2296-14-159.

36. Elo, S.; Kyngäs, H. The qualitative content analysis process. Journal of advanced nursing $\mathbf{2 0 0 8 , 6 2 ,}$ 107-115, doi:10.1111/j.1365-2648.2007.04569.x.

37. Creswell, J. Educational Research Planning, Conducting, and Evaluating Quantitative and Qualitative Research; Smith, P.A., Ed. Pearson Education Inc.: Boston,USA, 2012.

38. Kvale S, B.S. Interviews: Learning the Craft of Qualitative Research Interviewing; Sage: Los Angeles, 2009.

39. Graneheim, U.H.; Lundman, B. Qualitative content analysis in nursing research: concepts, procedures and measures to achieve trustworthiness. Nurse education today 2004, 24, 105-112, doi:10.1016/j.nedt.2003.10.001.

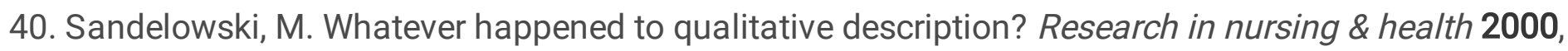
23, 334-340.

41. Hsieh, H.F.; Shannon, S.E. Three approaches to qualitative content analysis. Qualitative health research 2005, 15, 1277-1288, doi:10.1177/1049732305276687.

42. Hughes, J.R. Clinical significance of tobacco withdrawal. Nicotine \& tobacco research : official journal of the Society for Research on Nicotine and Tobacco 2006, 8, 153-156, doi:10.1080/14622200500494856. 
43. Koob, G.F.; Le Moal, M. Drug abuse: hedonic homeostatic dysregulation. Science (New York, N. Y.) 1997, 278, 52-58, doi:10.1126/science.278.5335.52.

44. Cahill, K.; Stevens, S.; Perera, R.; Lancaster, T. Pharmacological interventions for smoking cessation: an overview and network meta-analysis. The Cochrane database of systematic reviews 2013, 10.1002/14651858.CD009329.pub2, Cd009329, doi:10.1002/14651858.CD009329.pub2.

45. Fiore, M.C.; Jaén, C.R. A clinical blueprint to accelerate the elimination of tobacco use. Jama 2008, 299, 2083-2085, doi:10.1001/jama.299.17.2083.

46. Edwards, S.A.; Bondy, S.J.; Callaghan, R.C.; Mann, R.E. Prevalence of unassisted quit attempts in population-based studies: a systematic review of the literature. Addictive behaviors 2014, 39, 512519, doi:10.1016/j.addbeh.2013.10.036.

47. Hammond, D.; McDonald, P.W.; Fong, G.T.; Borland, R. Do smokers know how to quit? Knowledge and perceived effectiveness of cessation assistance as predictors of cessation behaviour. Addiction (Abingdon, England) 2004, 99, 1042-1048, doi:10.1111/j.1360-0443.2004.00754.x.

48. Shaheen, K.; Oyebode, O.; Masud, H. Experiences of young smokers in quitting smoking in twin cities of Pakistan: a phenomenological study. BMC public health 2018, 18, 466, doi:10.1186/s12889-0185388-7.

49. Westmaas, J.L.; Bontemps-Jones, J.; Bauer, J.E. Social support in smoking cessation: reconciling theory and evidence. Nicotine \& tobacco research : official journal of the Society for Research on Nicotine and Tobacco 2010, 12, 695-707, doi:10.1093/ntr/ntq077.

50. vanDellen, M.R.; Boyd, S.M.; Ranby, K.W.; MacKillop, J.; Lipkus, I.M. Willingness to provide support for a quit attempt: A study of partners of smokers. J Health Psychol 2016, 21, 1840-1849, doi:10.1177/1359105314567209.

51. Shiffman, S. Dynamic influences on smoking relapse process. Journal of personality $2005,73,1715-$ 1748, doi:10.1111/j.0022-3506.2005.00364.x.

52. Dani, J.A.; De Biasi, M. Cellular mechanisms of nicotine addiction. Pharmacology, biochemistry, and behavior 2001, 70, 439-446, doi:10.1016/s0091-3057(01)00652-9.

53. Park, E.Y.; Lim, M.K.; Kim, B.M.; Jeong, B.Y.; Oh, J.K.; Yun, E.H. Factors Related to Relapse After 6 Months of Smoking Cessation Among Men in the Republic of Korea: A Cross-Sectional Study. Medicine (Baltimore) 2015, 94, e1180, doi:10.1097/md.0000000000001180.

54. Hitchman, S.C.; Fong, G.T.; Zanna, M.P.; Thrasher, J.F.; Laux, F.L. The relation between number of smoking friends, and quit intentions, attempts, and success: findings from the International Tobacco Control (ITC) Four Country Survey. Psychology of addictive behaviors : journal of the Society of Psychologists in Addictive Behaviors 2014, 28, 1144-1152, doi:10.1037/a0036483.

55. Holahan, C.K.; Holahan, C.J.; Li, X.; Jung, S. Social influences on smoking in American workers: the role of the presence of smokers in the workplace and in the home. American journal of health promotion : AJHP 2013, 28, 105-107, doi:10.4278/ajhp.120604-ARB-283.

56. van den Brand, F.A.; Nagtzaam, P.; Nagelhout, G.E.; Winkens, B.; van Schayck, C.P. The Association of Peer Smoking Behavior and Social Support with Quit Success in Employees Who Participated in a 
Smoking Cessation Intervention at the Workplace. Int J Environ Res Public Health 2019, 16, doi:10.3390/ijerph16162831.

57. Monden, C.W.; de Graaf, N.D.; Kraaykamp, G. How important are parents and partners for smoking cessation in adulthood? An event history analysis. Preventive medicine 2003, 36, 197-203, doi:10.1016/s0091-7435(02)00026-9.

58. Memon, A.; Barber, J.; Rumsby, E.; Parker, S.; Mohebati, L.; de Visser, R.O.; Venables, S.; Fairhurst, A.; Lawson, K.; Sundin, J. What factors are important in smoking cessation and relapse in women from deprived communities? A qualitative study in Southeast England. Public health 2016, 134, 39-45, doi:10.1016/j.puhe.2016.01.014.

59. Grandi, S.M.; Filion, K.B.; Gervais, A.; Joseph, L.; O'Loughlin, J.; Paradis, G.; Rinfret, S.; Pilote, L.; Grondin, F.R.; Lutchmedial, S., et al. Weight change in patients attempting to quit smoking postmyocardial infarction. The American journal of medicine 2014, 127, 641-649.e641, doi:10.1016/j.amjmed.2014.02.032.

60. Cook, J.W.; Fucito, L.M.; Piasecki, T.M.; Piper, M.E.; Schlam, T.R.; Berg, K.M.; Baker, T.B. Relations of alcohol consumption with smoking cessation milestones and tobacco dependence. Journal of consulting and clinical psychology 2012, 80, 1075-1085, doi:10.1037/a0029931.

61. Lynch, K.L.; Twesten, J.E.; Stern, A.; Augustson, E.M. Level of Alcohol Consumption and Successful Smoking Cessation. Nicotine \& tobacco research : official journal of the Society for Research on Nicotine and Tobacco 2019, 21, 1058-1064, doi:10.1093/ntr/nty142.

62. Kahler, C.W.; Borland, R.; Hyland, A.; McKee, S.A.; Thompson, M.E.; Cummings, K.M. Alcohol consumption and quitting smoking in the International Tobacco Control (ITC) Four Country Survey. Drug and alcohol dependence 2009, 100, 214-220, doi:10.1016/j.drugalcdep.2008.10.006.

63. Zimmerman, R.S.; Warheit, G.J.; Ulbrich, P.M.; Auth, J.B. The relationship between alcohol use and attempts and success at smoking cessation. Addictive behaviors 1990, 15, 197-207, doi:10.1016/0306-4603(90)90063-4.

64. Kouvonen, A.; Kivimäki, M.; Virtanen, M.; Pentti, J.; Vahtera, J. Work stress, smoking status, and smoking intensity: an observational study of 46,190 employees. Journal of epidemiology and community health 2005, 59, 63-69, doi:10.1136/jech.2004.019752.

65. Boo, S.; Oh, H. Women's Smoking: Relationships Among Emotional Labor, Occupational Stress, and Health Promotion. Workplace health \& safety 2019, 67, 361-370, doi:10.1177/2165079918823214.

66. Cohen, S.; Lichtenstein, E. Perceived stress, quitting smoking, and smoking relapse. Health psychology : official journal of the Division of Health Psychology, American Psychological Association 1990, 9, 466-478, doi:10.1037//0278-6133.9.4.466.

67. Cooper, J.; Borland, R.; McKee, S.A.; Yong, H.H.; Dugué, P.A. Depression motivates quit attempts but predicts relapse: differential findings for gender from the International Tobacco Control Study. Addiction (Abingdon, England) 2016, 111, 1438-1447, doi:10.1111/add.13290.

68. Hartmann-Boyce, J.; Stead, L.F.; Cahill, K.; Lancaster, T. Efficacy of interventions to combat tobacco addiction: Cochrane update of 2013 reviews. Addiction (Abingdon, England) 2014, 109, 1414-1425, 
doi:10.1111/add.12633.

69. Wang, I.J.; Gjengedal, E.; Larsen, T. 'Passed and cleared' - Former tobacco smokers' experience in quitting smoking. Global health promotion 2014, 21, 57-65, doi:10.1177/1757975914523480.

70. Lancaster, T.; Stead, L.; Silagy, C.; Sowden, A. Effectiveness of interventions to help people stop smoking: findings from the Cochrane Library. BMJ (Clinical research ed.) 2000, 321, 355-358, doi:10.1136/bmj.321.7257.355.

71. Stead, L.F.; Bergson, G.; Lancaster, T. Physician advice for smoking cessation. The Cochrane database of systematic reviews 2008, 10.1002/14651858.CD000165.pub3, Cd000165, doi:10.1002/14651858.CD000165.pub3.

72. Rice, V.H.; Stead, L.F. Nursing interventions for smoking cessation. The Cochrane database of systematic reviews 2008, 10.1002/14651858.CD001188.pub3, Cd001188, doi:10.1002/14651858.CD001188.pub3.

73. Stead, L.F.; Buitrago, D.; Preciado, N.; Sanchez, G.; Hartmann-Boyce, J.; Lancaster, T. Physician advice for smoking cessation. The Cochrane database of systematic reviews 2013, 2013, Cd000165, doi:10.1002/14651858.CD000165.pub4.

74. Stead, L.F.; Perera, R.; Bullen, C.; Mant, D.; Hartmann-Boyce, J.; Cahill, K.; Lancaster, T. Nicotine replacement therapy for smoking cessation. The Cochrane database of systematic reviews 2012, 11, Cd000146, doi:10.1002/14651858.CD000146.pub4.

75. Barboza, J.L.; Patel, R.; Patel, P.; Hudmon, K.S. An update on the pharmacotherapeutic interventions for smoking cessation. Expert opinion on pharmacotherapy 2016, 17, 1483-1496, doi:10.1080/14656566.2016.1197203.

76. Sieminska, A.; Buczkowski, K.; Jassem, E.; Lewandowska, K.; Ucinska, R.; Chelminska, M. Patterns of motivations and ways of quitting smoking among Polish smokers: A questionnaire study. BMC public health 2008, 8, doi:10.1186/1471-2458-8-274.

\section{Figures}




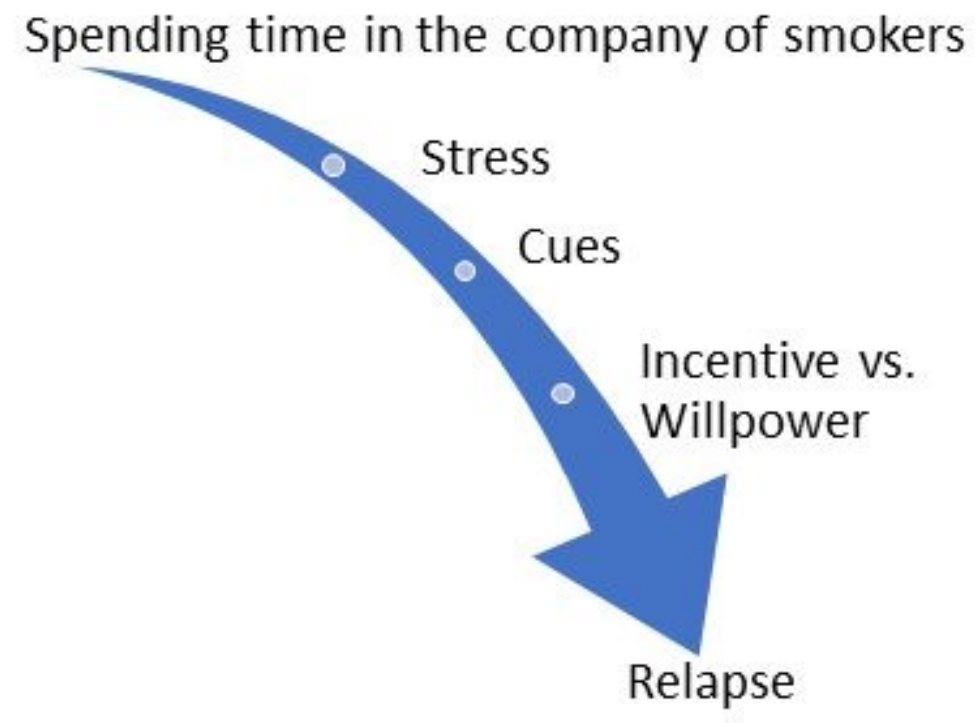

Figure 1

A scenario that induces a smoking relapse

\section{Supplementary Files}

This is a list of supplementary files associated with this preprint. Click to download.

- ISSMCOREQChecklist.pdf 